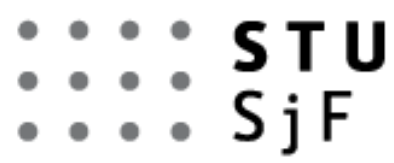

DE GRUYTER OPEN

\title{
ANALYSIS OF PHARMACEUTICAL EXCIPIENT MCC AVICEL PH102 USING COMPACTION EQUATIONS
}

\author{
PECIAR Peter ${ }^{1}$, ECKERT Maroš ${ }^{1}$, FEKETE Roman $^{1}$, HRNČIAR Viliam $^{2}$ \\ ${ }^{I}$ Slovak University of Technology in Bratislava, Faculty of Mechanical Engineering, Institute of Process \\ Engineering, Nám. Slobody 17, 81231 Bratislava, Slovakia, e-mail: peter.peciar@stuba.sk, \\ maros.eckert@stuba.sk,roman.fekete@stuba.sk \\ ${ }^{2}$ Slovak University of Technology in Bratislava, Faculty of Mechanical Engineering, Institute of Technologies \\ and Materials, Pionierska 15,83102 Bratislava, Slovakia, e-mail: viliam.hrnciar@stuba.sk
}

\begin{abstract}
This paper focuses on the characterization of the tabletting process and analysis one of the most common pharmaceutical excipients MCC Avicel PH102 by Heckel, Kawakita, Cooper-Eaton and Adams compaction equations. Experimental material was determined by measuring its parameters as particle size distribution, angle of wall friction and flow properties and for more detailed characteristics of the material particles, microscopy images of the powder before and after compressing were created.
\end{abstract}

KEYWORDS: Compaction equation, tabletting, angle of internal friction, angle of wall friction

\section{$1 \quad$ Introduction}

Tablets are among the most commonly used dosage forms. They are solid, mechanically strong drugs of different sizes and shapes. Production of tablets begins with the preparation of a mixture for tablets. Mixture is prepared either by simply mixing the drug and the excipients in a given ratio or by mixing the granulate with excipients. The most common excipients used for tabletting include microcrystalline cellulose (MCC). A very often used type is MCC Avicel PH102, which has the appropriate dosing and compressibility. Excipients can be classified by using compaction equations. Commonly used equations describe the volume compression reduction of the material under applied compacting pressure. The parameters calculated from equations reflect the character of the pressed material. These data allow comparing different materials for their suitability for tabletting.

\section{Descriptions of powder compaction}

The process of powder compression into a tablet can be generally divided into four predominant stages [18]. Although they are defined as sequential, they can in reality occur simultaneously. These stages are; rearrangement of particles, plastic deformation and (or) fragmentation and elastic deformation and elastic shape recovery following unloading (Fig. 1).

After filling the powder into the die cavity, the consecutive action of the punch causes rearrangement of the particles. Soon thereafter, the system reaches a state where its capacity to rearrange is exhausted as the particles are constrained or locked into position by more structurally stable contact with their neighbors. This junction can be referred to as a constrained state. During this initial stage a degree of fragmentation can occur. 


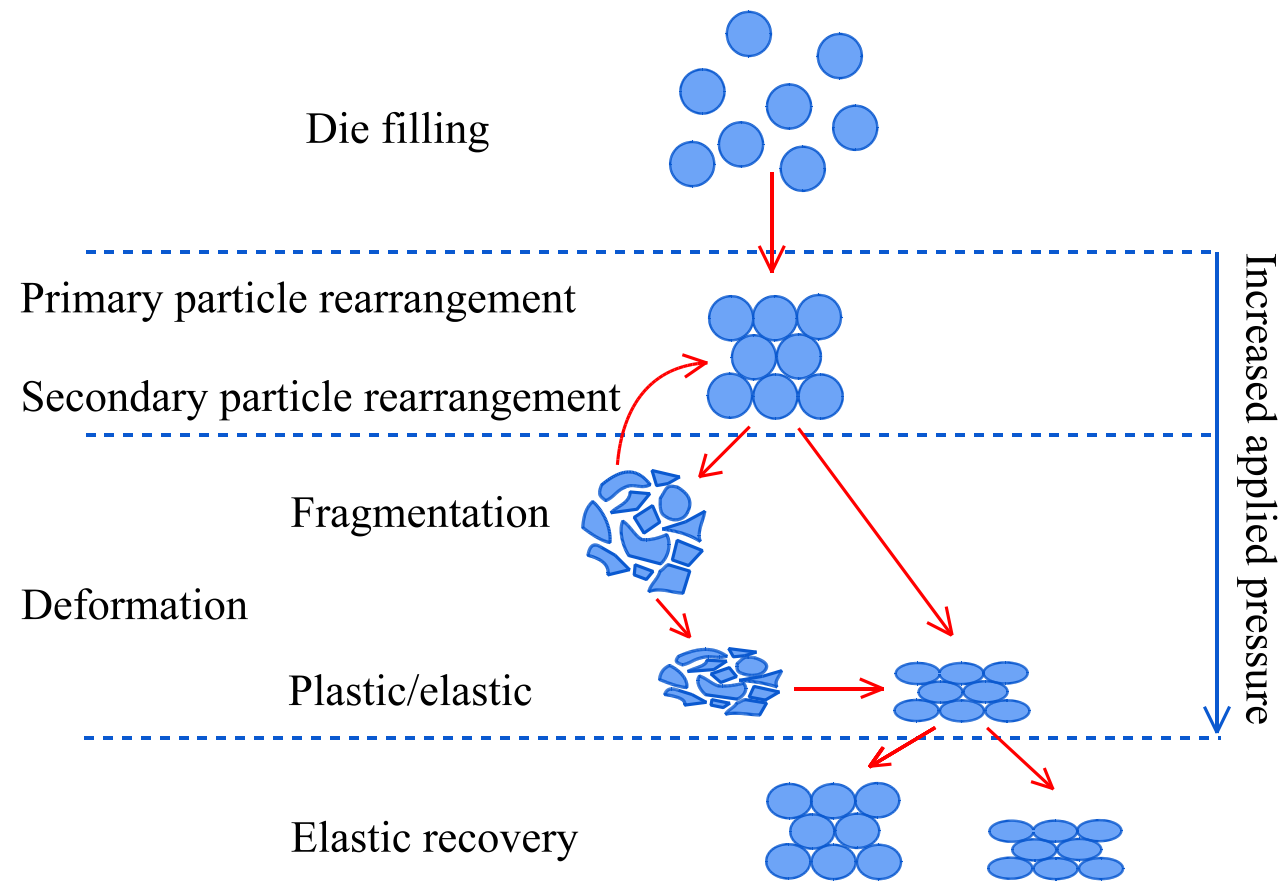

Fig. 1 Schematic illustration of the powder compression cycle

Upon reaching the constrained state, any further reduction in the porosity of the powder bed can only occur as a result of a mechanical change in the structure of each of its composing particles. Such a change must take place in response to the increasing pressure on the powder. For simplicity two main ways of absorbing external loads can be considered; deformation and fragmentation of the particles. If the particles are plastic or elastic in nature they will deform to absorb the increasing applied load. If a particle is brittle in nature, it will break into smaller pieces which then fill up the pores. Assuming the applied force is large enough, the particles can undergo one or all of these structural changes. It is during this transitional phase that bonding between the contacting surfaces of the powder particles occurs, either as in the case of deformation, by an increased area of contact between the particles, or by an increase in the number of bonding sites, as in the case of breakage.

Finally, at maximum applied pressure, when the porosity is reduced to 5 - $10 \%$, i.e. when almost all pores are eliminated, the powder will no longer be an autonomous system of particles, but rather a single solid unit. Further compression past this point will invariably be controlled by the elastic deformation of this solid unit, as there is no other possibility for permanent structural change. Consequently, when the pressure is removed, the tablet begins to relax into its final dimensions.

The terms compressibility and compatibility are often used to describe a powder (Fig. 2). A very compressible powder is one that significantly densifies upon compression. Powders with very small particle size are normally very compressible. However, this does not mean that they are able to form tablets. The compactibility of a powder determines whether or not it can form a tablet. 


\section{Compressibility}
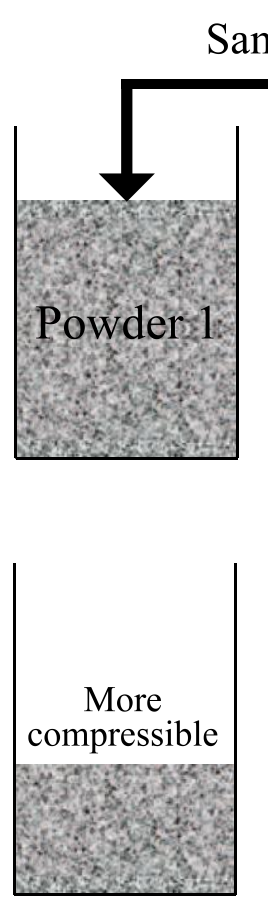

\section{Compactibility}
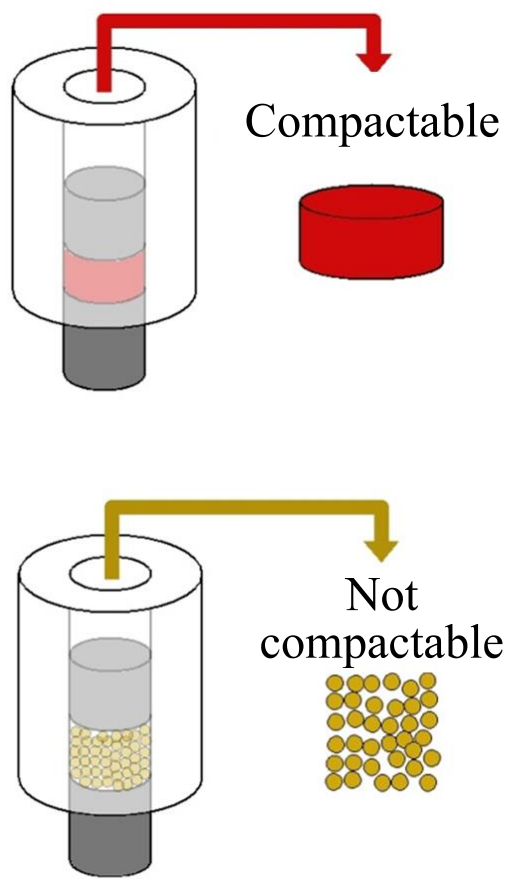

Fig. 2 Examples of compressibility and compactibility

\section{Compaction equations}

Compacting powders into a tablet form is a process of reducing porosity and of forming materials into a solid compact. The structure of powders changes during compression and densification takes place mainly due to the rearrangements of particles, their fragmentation and plastic deformation. The compression of powders into a tablet form is a complex and irreversible dynamic process. Several relationships between stress-strain, pressure-volume, pressure-porosity or pressure-density have been proposed to define the compaction behavior of powders, since natural strain is proportional to changes in powder-bed height or volume under applied pressure. Compaction equations put into relation the state of compaction parameters such as porosity, volume or density with respect to the applied pressure. In the interpretation of the data of compaction it is important to know what compaction mechanisms operate at different levels of pressure.

\subsection{Heckel equation}

The Heckel equation [9, 24, 25] is one of the most common equations describing the mechanism of reducing volume during compaction. It is based on the assumption that powder compression follows first-order kinetics with interparticulate voids as the reactant and the densification of the powder as the product. Then the degree of compaction with increasing compressing pressure is proportional to the porosity thusly:

$$
\frac{\mathrm{d} \rho_{r}}{\mathrm{~d} P}=k \varepsilon
$$


where $\rho_{r}$ is relative density at applied pressure $P$ and $\varepsilon$ is porosity. Relative density is defined as the ratio between the density of the compact at pressure $P$ and the true density of the solid particles. Porosity is given by:

$$
\varepsilon=\frac{\left(V_{p}-V_{s}\right)}{V_{p}}=1-\rho_{r}
$$

where $V_{p}$ is the volume of the powder at pressure $P$ and $V_{s}$ is the volume of the solid particles. Then the equation (1) can be expressed as:

$$
\frac{\mathrm{d} \rho_{r}}{\mathrm{~d} P}=k\left(1-\rho_{r}\right)
$$

and by solving the differential equation (3):

$$
\ln \left[\frac{1}{\left(1-\rho_{r}\right)}\right]=k P+A
$$

Plotting the value of $\ln \left[1 /\left(1-\rho_{r}\right)\right]$ against applied pressure $P$ leads to the plot with a linear section (Phase 2 - Plastic deformation) with a slope $k$ and intercept $A$ (Fig. 3). The reciprocal of the parameter $k$ expresses the constant dependence on the material known as yield pressure $P_{y}$, which is inversely related to the ability of the material to deform plastically under pressure. Thus, the lower values $P_{y}$ indicate the onset of plastic deformation at lower pressures. Intercept $A$ expresses the parameter dependent on the original compact volume during die filling and the initial particle rearrangement. The Heckel plot has three stages of densification described in Fig. 3.

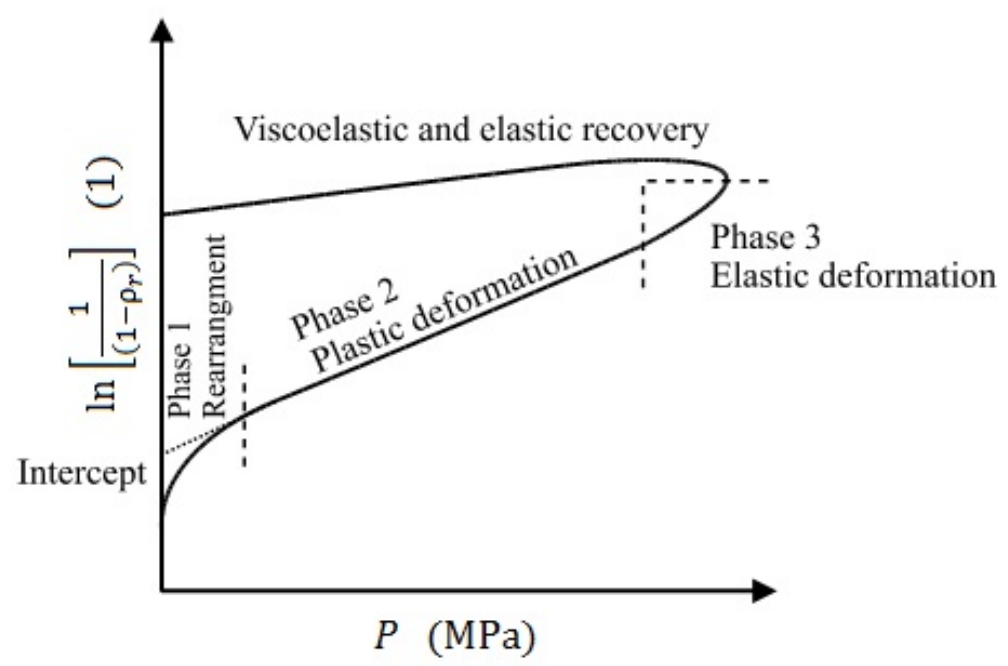

Fig. 3 A typical Heckel plot

\subsection{Kawakita equation}

The Kawakita equation $[9,24]$ was developed to study powder densification using the degree of reduction in volume $C$ expressed as:

$$
C=\frac{\left(V_{0}-V_{p}\right)}{V_{0}}=\frac{a b P}{(1+b P)}
$$


equation (5) can be rearranged to give:

$$
\frac{P}{C}=\frac{P}{a}+\frac{1}{a b}
$$

where $V_{0}$ is the initial volume of the powder and $V_{p}$ is the volume under compression. Constants $a$ and $b$ are obtained from the slope and intercept of the $P / C$ versus $P$ plot (Fig. 4). The constant $a$ expresses the minimum porosity of the powder before compressing and the value of $(1-a)$ indicates the initial relative density $\rho_{0}$ [14]. The constant $b$, also known as the coefficient of compression, is related to the plastic material properties. Its reciprocal expresses the pressure parameter $P_{k}$, which is the pressure required to reduce the volume of the powder by $50 \%$. For plastic materials, the value of $P_{k}$ is inversely proportional to the degree of plastic deformation during the compaction process, therefore lower values of $P_{k}$ indicate a higher degree of plastic deformation.

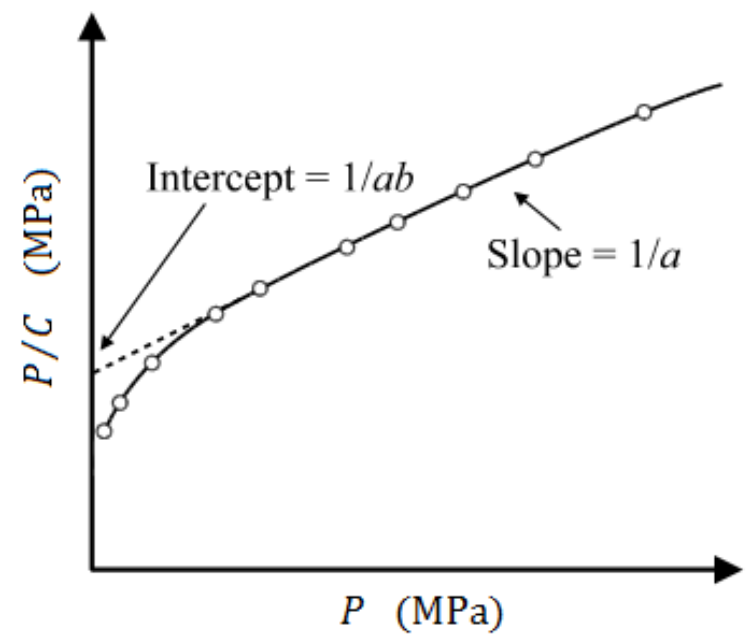

\subsection{Cooper-Eaton equation}

Fig. 4 A typical Kawakita plot

The Cooper-Eaton equation [24] assumes that the compression of powders follows a twostep process. The first step is the rearrangement of particles so that the particles fill those voids that are larger than or the same size as that of the particles. In the second stage there occurs deformation (elastic, plastic, fragmentation), whereby the voids that are smaller than that the particles are filled due to applied pressure. The Cooper-Eaton equation is expressed in the form:

$$
\frac{\frac{1}{\rho_{0}}-\frac{1}{\rho_{r}}}{\frac{1}{\rho_{0}}-1}=a_{1} \exp \left(-\frac{k_{1}}{P}\right)+a_{2} \exp \left(-\frac{k_{2}}{P}\right)
$$

where $\rho_{0}$ is the initial relative density of the powder (ratio between initial density of the powder and density of the solid particles), $\rho_{r}$ is the relative density at pressure $P$, constants $a_{1}, a_{2}$ indicate the proportion of the total compaction achieved by filling those voids that are larger or the same size $\left(a_{1}\right)$ and smaller $\left(a_{2}\right)$ than the actual particles. Constants $k_{1}$ and $k_{2}$ describe the pressures at which this two-stage densification is thought to occur. Graphical evaluation is the relationship between the applied pressure and fractional volume compression 
$(F V C)$, which is expressed by the left side of the equation (7). All of the constants can be determined by a non-linear plot (Fig. 5).

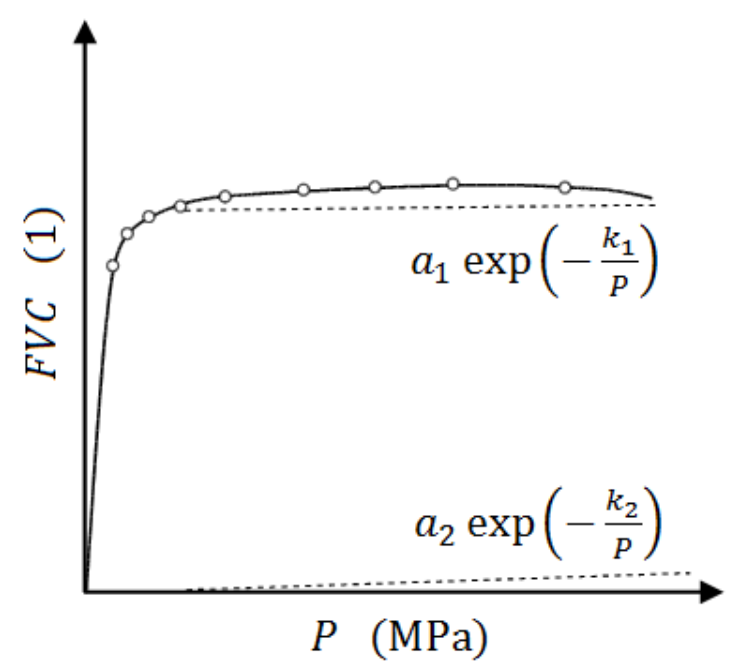

Fig. 5 A typical Cooper - Eaton plot

\subsection{Adams equation}

The Adams equation [3] was derived to estimate the fracture strength of single granules from in-die compression data. It assumes the bed of granules in the die as a series of parallel load-bearing columns. The equation derived was expressed as:

$$
\ln P=\ln \frac{\tau_{0}}{\alpha}+\alpha \varepsilon_{\mathrm{A}}+\ln \left[1-e^{\left(-\alpha \varepsilon_{\mathrm{A}}\right)}\right]
$$

where $P$ is the applied pressure and $\varepsilon_{\mathrm{A}}$ is the natural strain which is given by:

$$
\varepsilon_{\mathrm{A}}=\ln \left[\frac{H_{0}}{H_{P}}\right]
$$

and $H_{0}$ and $H_{P}$ are the initial and current height of the powder bed, respectively. Parameter $\tau_{0}$ shows single granule strength (also known as the Adams parameter) and parameter $\alpha$ is the friction coefficient. At higher values of natural strain, the last term of the equation (8) becomes negligible and can be omitted. The intercept and slope of this linear part of the profile were used to calculate the compression parameter $\tau_{0}$ (Fig. 6). 


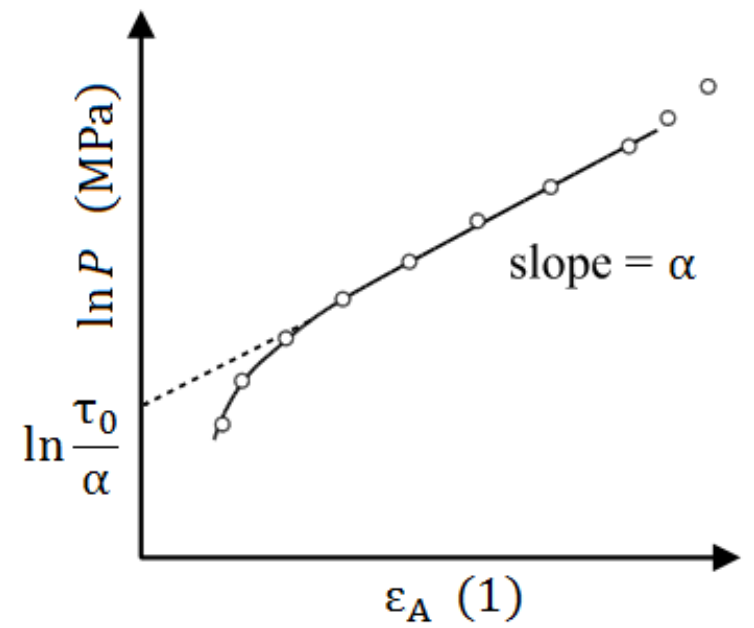

Fig. 6 A typical Adams plot

\section{$4 \quad$ Material and methods}

The compression behaviors of MCC Avicel PH102 were studied in the experiments described in this paper. This material was chosen for its widespread use as an excipient in tabletting. This is due to its very good flowability, compressibility and compatibility.

Table 1 summarizes the experimentally obtained parameters of the pharmaceutical powder MCC Avicel PH102. The median particle size $D_{V 50}$ and dimensions $D_{V 10}$ and $D_{V 90}$ were determined using a laser analyzer in order to define the particle size distribution of the powder. In Fig. 13 is a graphical output of the shear test, which provided the powder flow parameters and in Fig. 14 is a plot of normal stress versus shear stress during the wall friction test, from which the wall friction angle is obtained.

Tab. 1 Parameters of the pharmaceutical powder MCC Avicel PH102

\begin{tabular}{llrr}
\hline Parameter & Symbol & Unit & Value \\
\hline \multirow{2}{*}{ Particle size distribution } & $D_{V 10}$ & $(\mu \mathrm{m})$ & 35 \\
\cline { 2 - 4 } & $D_{V 50}$ & $(\mu \mathrm{m})$ & 116 \\
\cline { 2 - 4 } & $D_{V 90}$ & $(\mu \mathrm{m})$ & 247 \\
\hline Bulk density & $\rho_{\mathrm{B}}$ & $\left(\mathrm{kg} / \mathrm{m}^{3}\right)$ & 300 \\
\hline Particle density & $\rho_{\mathrm{P}}$ & $\left(\mathrm{kg} / \mathrm{m}^{3}\right)$ & 1590 \\
\hline Cohesion & $\tau_{\mathrm{c}}$ & $(\mathrm{kPa})$ & 1,35 \\
\hline Major principal stress & $\sigma_{1}$ & $(\mathrm{kPa})$ & 15,4 \\
\hline Unconfined yield strength & $\sigma_{\mathrm{c}}$ & $(\mathrm{kPa})$ & 4,08 \\
\hline Flow factor (flowability) & $f f$ & $(1)$ & 3,79 \\
\hline Angle of internal friction (linearized) & $\varphi_{\text {lin }}$ & $\left({ }^{\circ}\right)$ & 22,9 \\
\hline Angle of internal friction (effective) & $\varphi_{\mathrm{e}}$ & $\left({ }^{\circ}\right)$ & 30,7 \\
\hline Angle of internal friction (steady-state) & $\varphi_{\mathrm{sf}}$ & $\left({ }^{\circ}\right)$ & 29,4 \\
\hline Wall friction angle & $\varphi_{\mathrm{x}}$ & $(\mu \mathrm{m})$ & 14,6 \\
\hline Roughness (wall friction test) & $R a$ & & 0,28 \\
\hline
\end{tabular}




\subsection{Particle size distribution}

The particle size distribution of the pharmaceutical powder used in this paper is given in Tab. 1. It was measured using the Malver Mastersizer 3000 particle size analyzer. The Mastersizer uses the technique of laser diffraction to measure the size of particles. It does this by measuring the intensity of light scattered as a laser beam passes through a dispersed particulate sample. This data is then analyzed to calculate the size of the particles that created the scattering pattern. In Fig. 7 is the particle size distribution as a function of volume density in the sample.

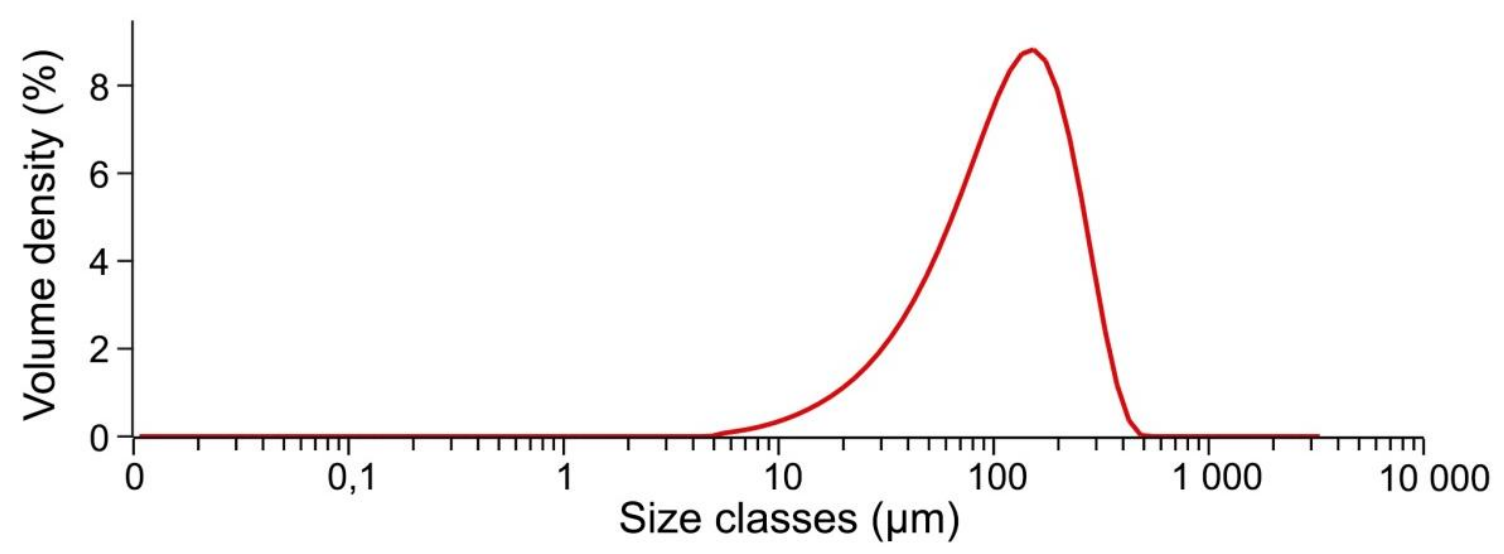

Fig. 7 Particle size distribution of MCC Avicel PH 102 measured by Malvern Mastersizer 3000

\subsection{Particle shape and surface structure}

The behaviour of the powdered material affects not only the particle size distribution, but also the particles' shape and surface structure. To observe the structure of the powder was used scanning electron microscopy $\left(\mathrm{Joel}^{\mathrm{R}}\right)$. This microscope uses a beam of accelerated electrons radiated on the powder sample, which was prepared by applying a layer of conductive powder (platinum). Secondary reflected electrons from the sample surface are captured by detection equipment and further adjusted to the form of digital images. In Fig. 8 is the image of the bulk powder MCC Avicel PH102 at 200 times magnification. In order to compare changes in the structure of the powder after compaction, in Fig. 9 is the image of the broken tablet compressed at a pressure of $160 \mathrm{MPa}$ and 200 times magnification. It is obvious that the powder achieved a significant reduction in porosity and that the particles were plastically deformed, while the number of inter-particle contacts and bonds increased. Thus tablet thus achieved significant strength and became a compact unit. 


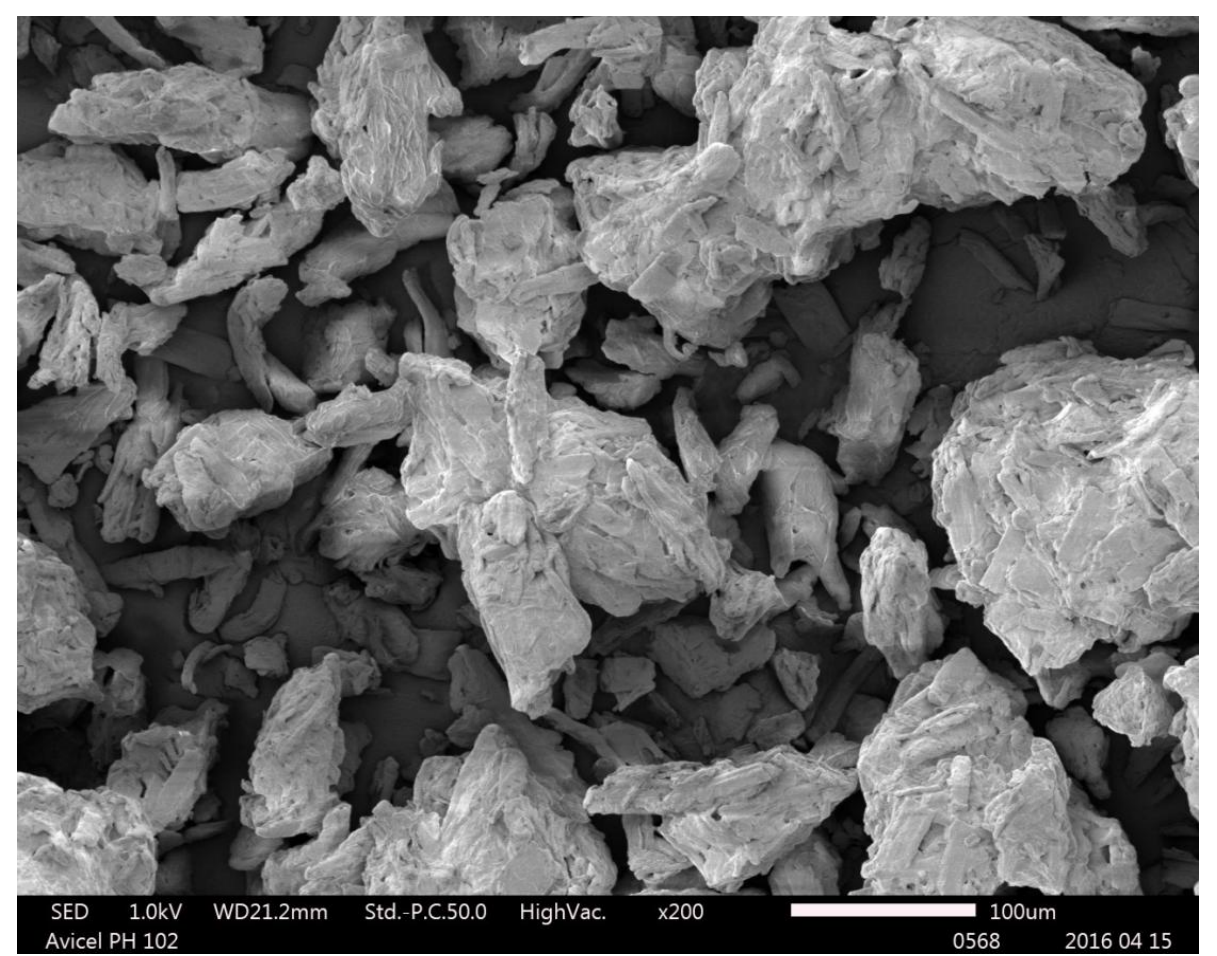

Fig. 8 Electron microscopy image of the bulk powder MCC Avicel PH 102

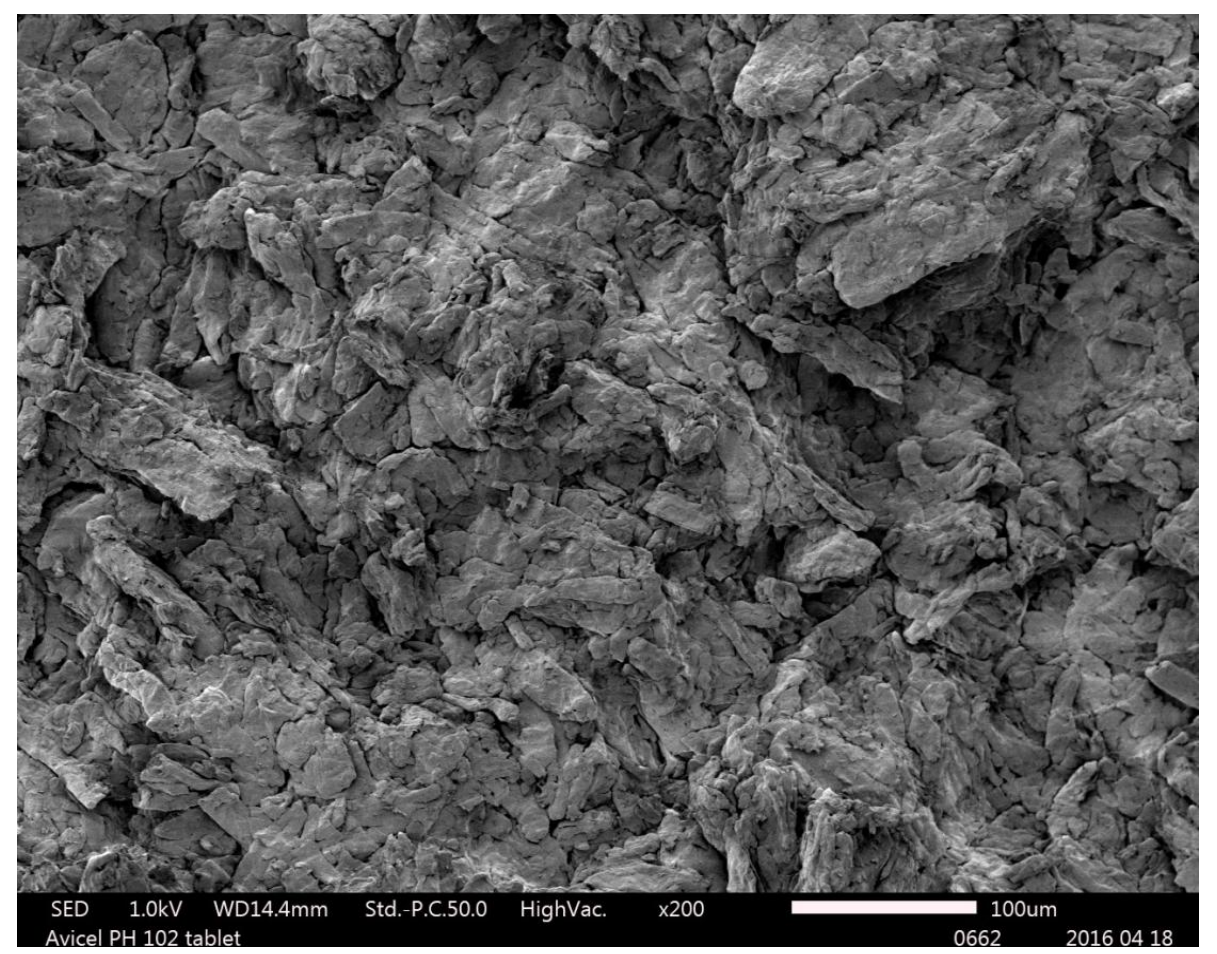

Fig. 9 Electron microscopy image of the crushed tablet from MCC Avicel PH 102

\subsection{Shear cell test and wall friction test}

Determination of the excipient's flow properties was performed using an FT 4 Powder Rheometer. The shear test measures the shear stress needed to cause failure of the powder, i.e. the powder particles start to move relative to one another as a function of the applied normal stress. After filling in the test vessel the powder is pre-consolidated by a vented piston 
at $3 \mathrm{kPa}$. Subsequently measuring the shear stress for five levels of normal stress; 3, 4, 5, 6 and $7 \mathrm{kPa}$ was carried out by a Shear cell (Fig. 11). In that way, five data points are obtained which can be plotted in a two dimensional coordinate system as normal stress $\sigma$ and corresponding shear stress $\tau$. The line passing through these five points is called the yield locus (Fig. 10) and is the basis of the parameters obtained during the shear test. The principle of the measurements described above is based on Jenike's assumptions regarding the flow measurements of bulk solids. Therefore, the obtained data is analyzed and interpreted in the same way as data from a Jenike shear tester [11, 25, 32].

Among the parameters obtained from the plot $\sigma$ versus $\tau$ include major principal stress $\sigma_{1}$, which is the largest of all normal stresses acting during steady-state flow in all possible cutting planes of the specimen. Another parameter is the unconfined yield strength $\sigma_{c}$, which expresses the stress causing the consolidated bulk solid specimen to move. Flow properties can be qualified by flow factor $f f$, which is defined as:

$$
f f=\frac{\sigma_{1}}{\sigma_{c}}
$$

A powder with a higher $f f$, under the same $\sigma_{1}$, exhibits better flow properties. Powders with $f f<1$ are non-flowing, while powders with $f f>10$ are free-flowing [11, 22, 25]. Further parameters describing the flow properties and their measured values for the MCC Avicel PH102 are in Tab. 1.

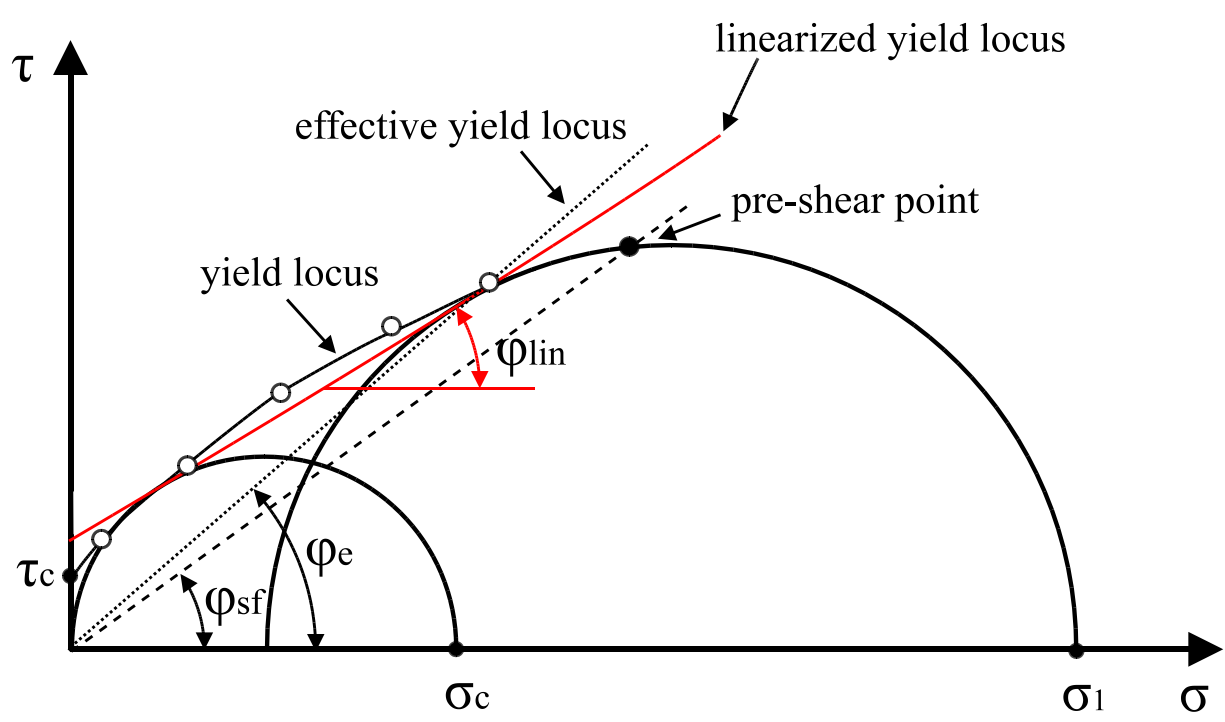

Fig. 10 An illustration of different flow parameters obtained from the shear cell test

The wall friction test provides a measurement of the sliding resistance between the powder and the surface of the process equipment. The wall friction test is similar to the shear test. The output of the wall friction test is the kinematic angle of wall friction $\varphi_{x}$. This parameter quantifies the effort required to move a bulk solid across the surface of a specific wall material. Measurement is carried out by a wall friction head (Fig. 12), which loads the surface of powdered material filled in the test vessel to normal stress $\sigma_{\mathrm{x}}$. The wall friction head starts to rotate slowly, thus the shear stress $\tau_{x}$ appears and a shear plane is formed between the wall friction head and the powder surface. The measurement is performed for different normal stresses and their corresponding shear stresses, and then the angle of wall friction is determined as: 


$$
\varphi_{\mathrm{x}}=\tan ^{-1}\left(\frac{\tau_{\mathrm{x}}}{\sigma_{\mathrm{x}}}\right)
$$

The measured value of the angle of wall friction and the roughness of the material for which the angle was measured is shown in Tab. 1.

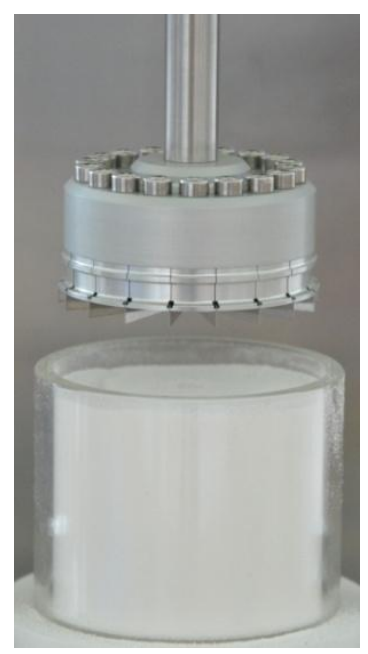

a)

Fig. 11 Shear cell test

a) shear cell head,

b) principle of shear cell test

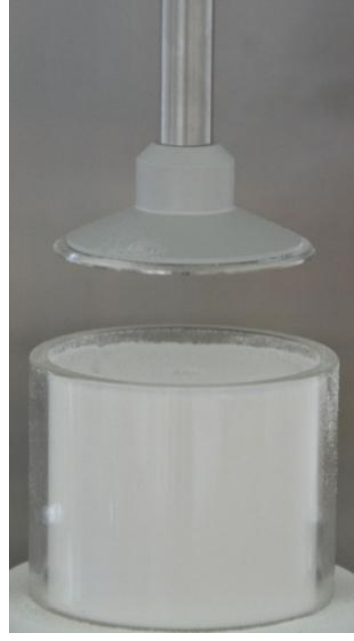

a)

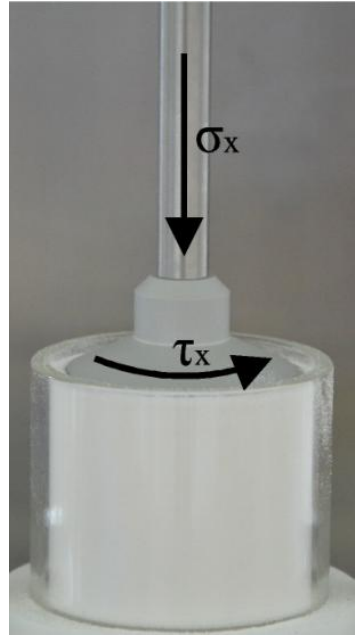

b)

Fig. 12 Wall friction test

a) wall friction head,

b) principle of wall friction test

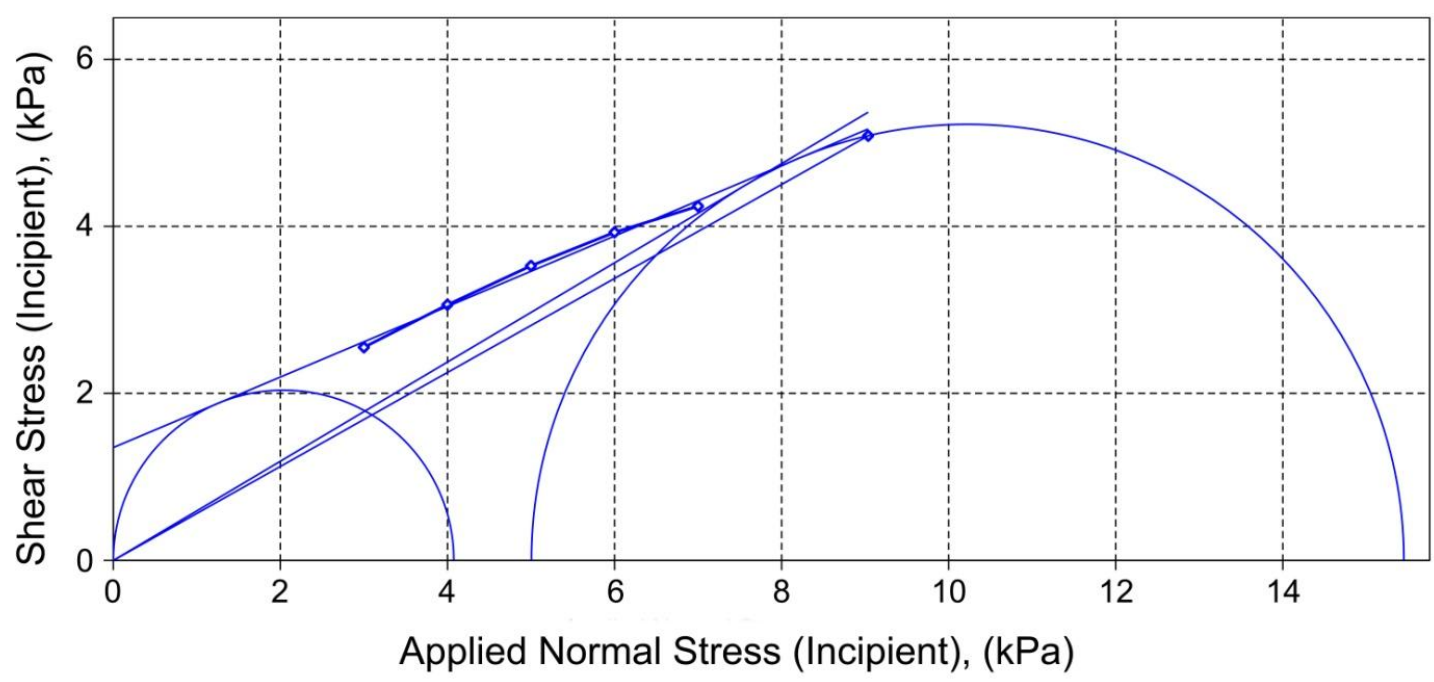

Fig. 13 Graphical results of the Shear test (FT4 Powder Rheometer) 


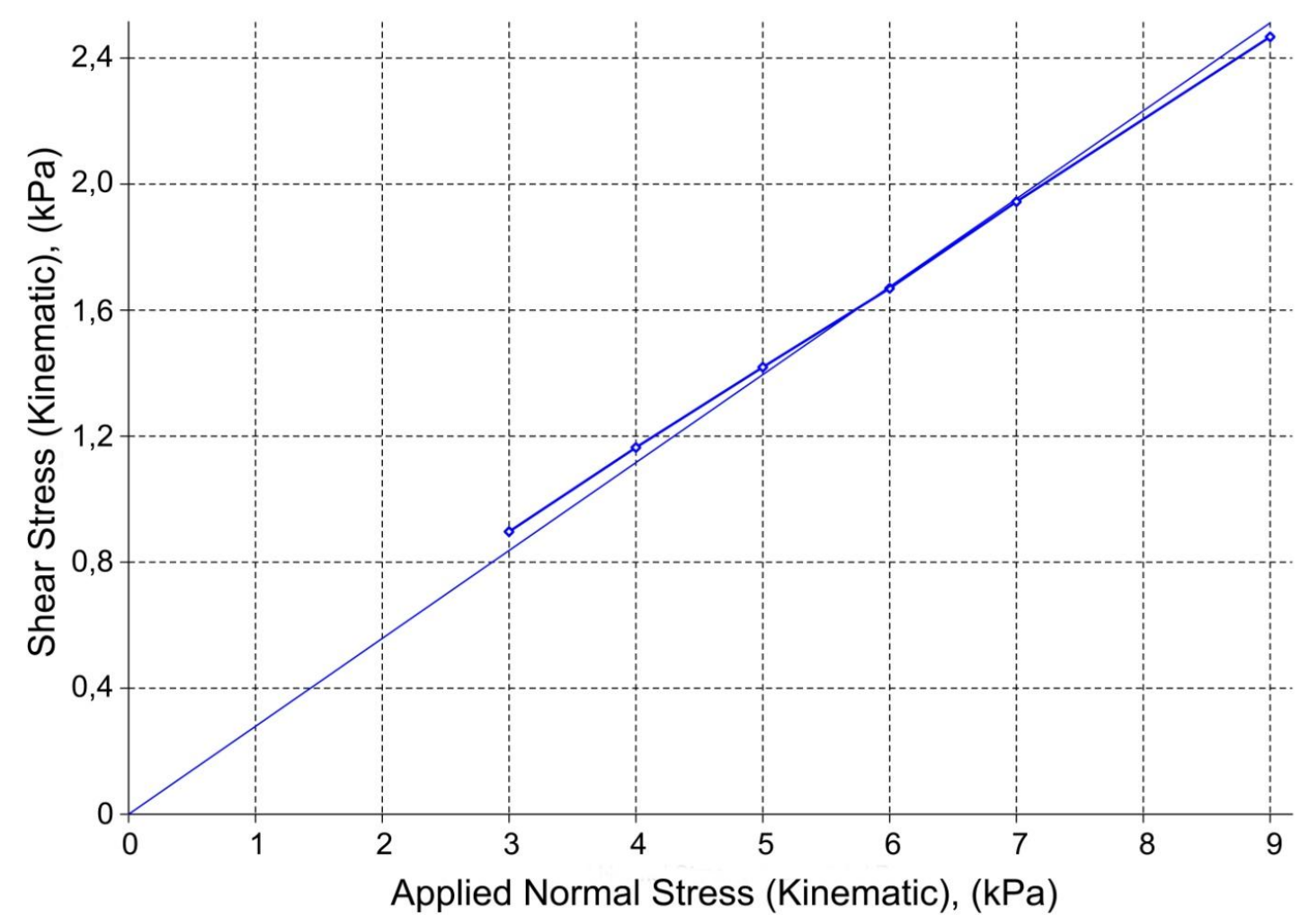

Fig. 14 Graphical result of the Wall friction test (FT4 Powder Rheometer)

\subsection{Experimental measurements}

The measurement is performed on a KISTLER electromechanical press (Fig. 15a). The press contains a force sensor and a sensor of punch position. The maximum press force is $60 \mathrm{kN}$ and the range of displacement of the punch is $200 \mathrm{~mm}$. Compression of the powder was carried out on a die tool (Fig. 15b). It consists of a steel die and a punch with a diameter of $20 \mathrm{~mm}$.

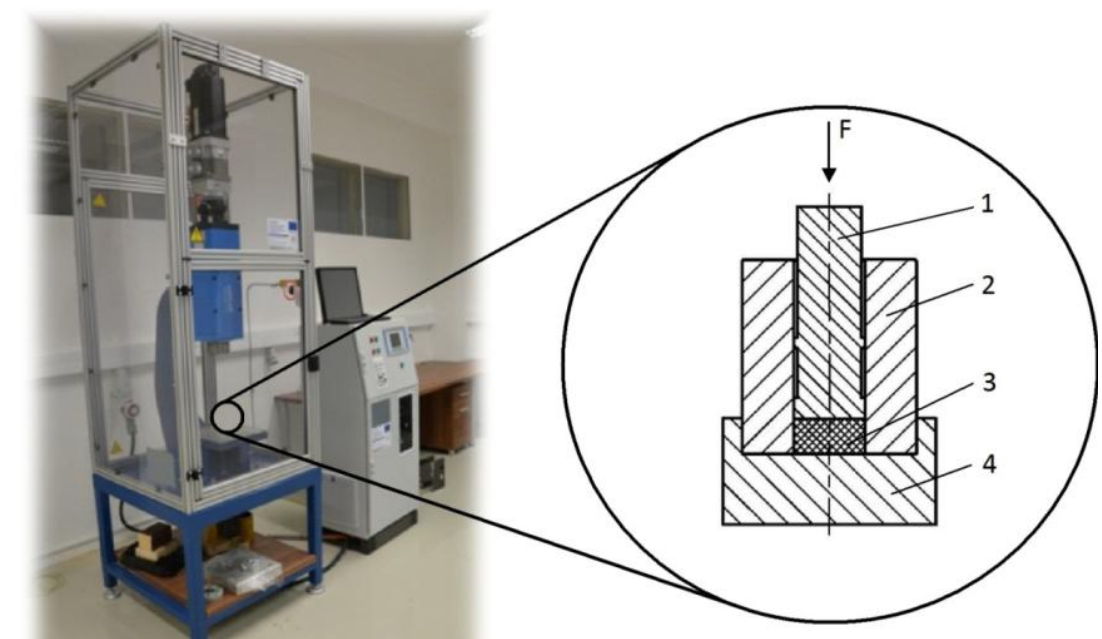

a)

b)

Fig. 15. Experimental station

a) electomechanical press KISTLER, b) tabletting die: 1 - compressing punch,

2 - die, 3 - compressing powder, 4 - base of the tabletting die 


\section{$5 \quad$ Results and discussion}

\subsection{Compaction equations parameters}

Experimental measurements were carried out at a constant compression speed of $100 \mathrm{~mm} / \mathrm{s}$ and the pressing force was $50 \mathrm{kN}$ which, after calculation with respect to the surface of the compressing punch, represent a pressure of $159.16 \mathrm{MPa}$. Parameters of compaction such as relative density and powder volume were determined by the measured values of the punch position. Consequently, plots of each compaction equation were made and the parameters of the equations were determined by regression analysis.

In the case of linear regression analyzes regression areas were chosen in order to fit the condition of $R^{2}>0.999$ with the relevant area bounded by vertical lines in the graphs. The regression equations with the individual parameters are shown in Tab. 2.

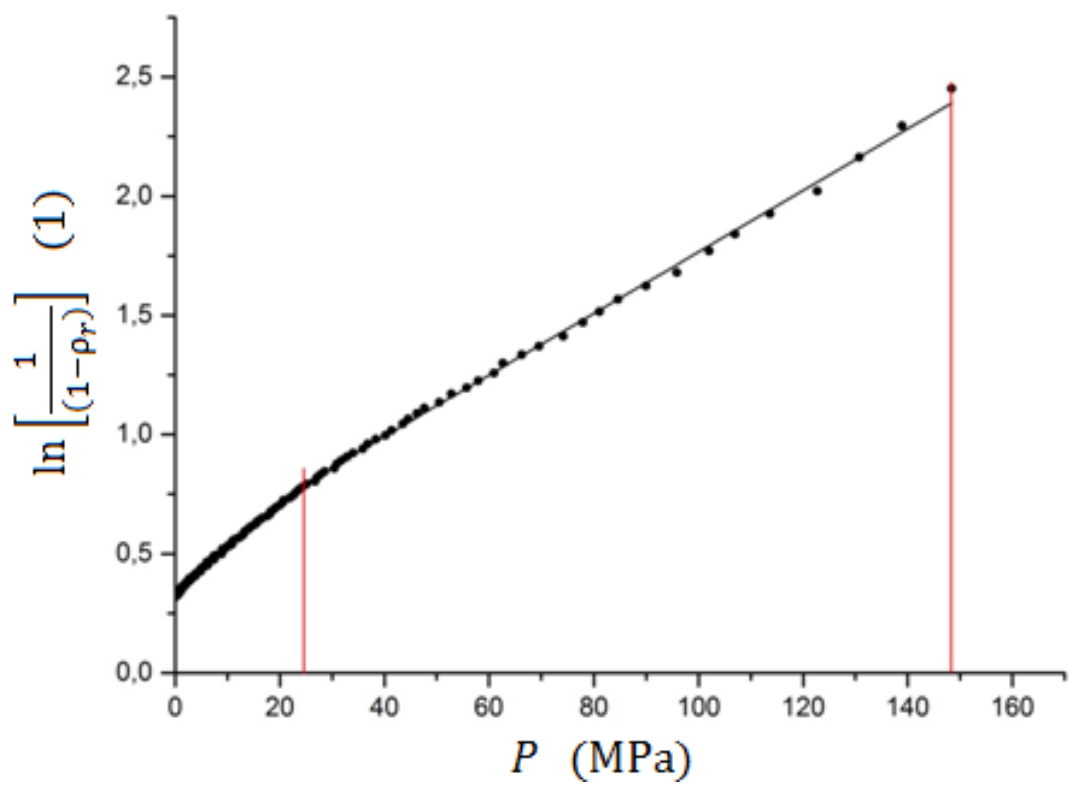

Fig. 16 Heckel plot of the MCC Avicel PH 102

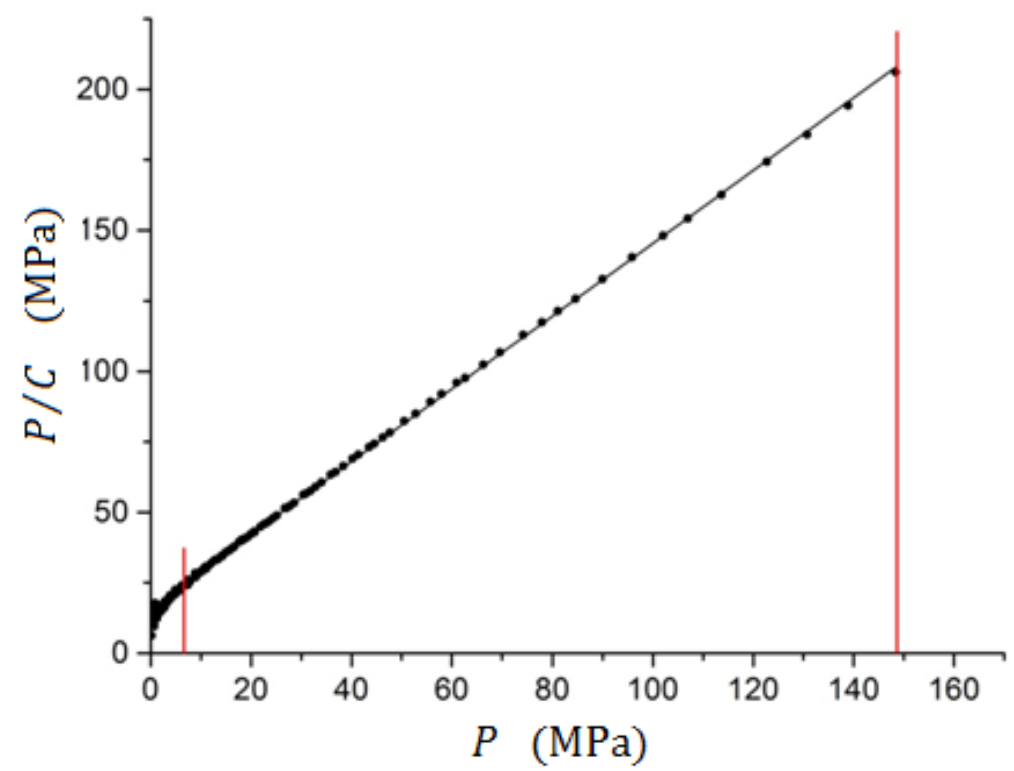

Fig. 17 Kawakita plot of the MCC Avicel PH 102 


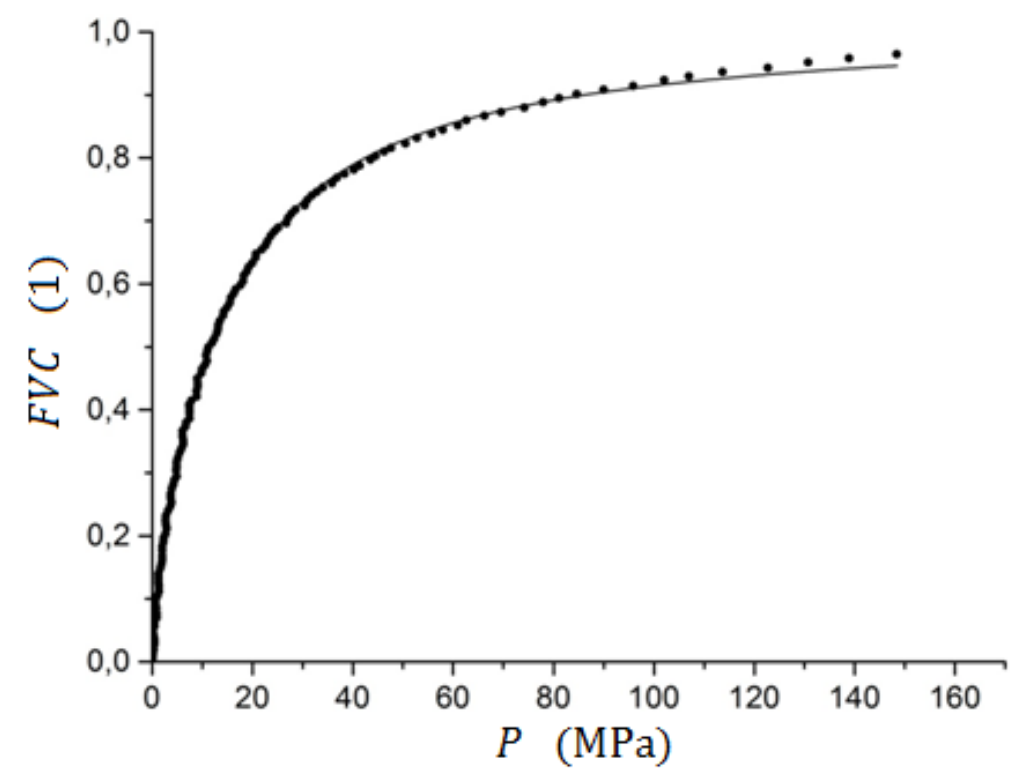

Fig. 18 Cooper-Eaton plot of the MCC Avicel PH 102

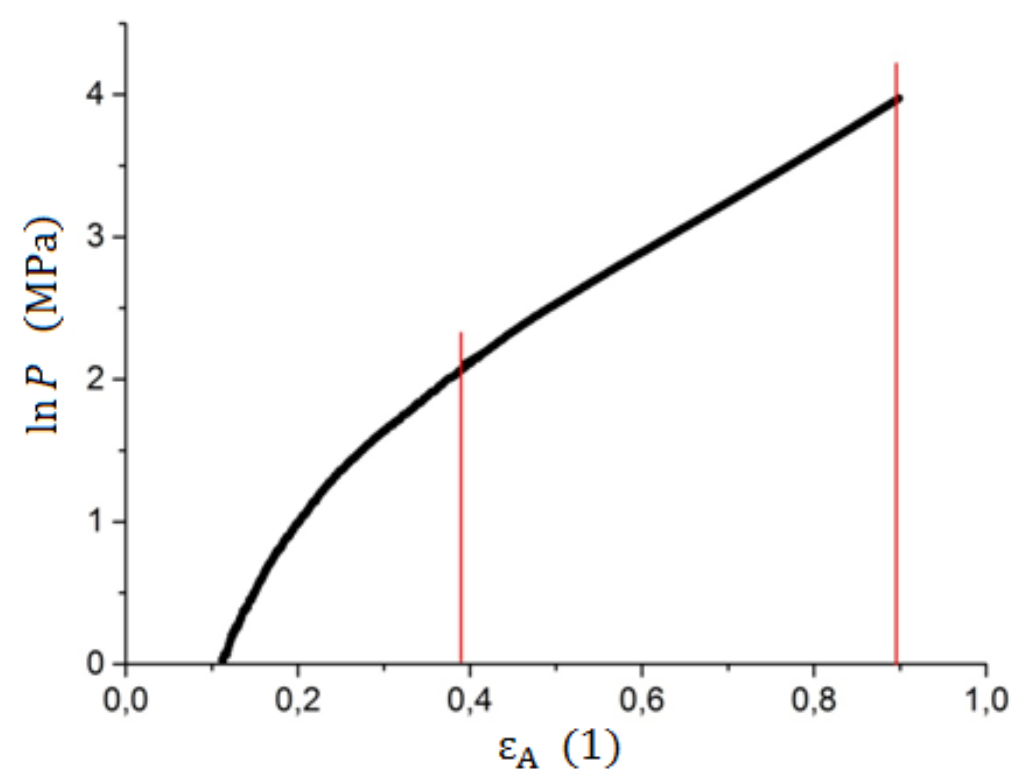

Fig. 19 Adams plot of the MCC Avicel PH 102

Based on the graphical results it can be stated that all compaction equations can be used if required for the particular compaction parameters for the MCC Avicel PH102 pharmaceutical material.

On the basis of graphical evaluation it can be concluded that all the compaction equations are suitable for describing the process of compressing powdered material on the MCC Avicel PH 102. In the case of the Heckel and Kawakita plots, there is a significant linear correlation describing the main mechanism of the compaction through plastic deformation of the powder particles. The Heckel plot shows that the curve begins to adopt a tendency corresponding to the elastic deformation of the solid compact and therefore further compression does not affect the plastic deformation of the particles and also does not affect the formation of new bonds between the particles. The Kawakita equation with a very good accuracy gives the initial relative density $\rho_{0}$ and indicates that a volume reduction of $50 \%$ was achieved at a relatively 
low compression pressure, which is primary caused by rearrangement and by filling the voids of the particles. A more detailed description of the mechanisms of densification is provided by the Cooper-Eaton plot. It reflects that plastic deformation occurring at low applied pressures has a greater impact on the overall compaction. Fragmentation occurred to a very small degree, because MCC Avicel PH102 contains elastic particles and thus there was no overlapping of the three mechanisms of compaction, which caused a significant transition between these mechanisms.

The Adams equation is primarily intended to indicate the stress needed to crack granules during tablet compression. The Adams parameter $\tau_{0}$ expresses the initial stage of plastic particle deformation in terms of failure stress and is thus related to the single pellet yield pressure. It can be concluded that the Adams parameter $\tau_{0}$ in a similar way as the Kawakita $P_{k}$ parameter represents useful approximations of the plasticity of the powder particles. However, in the case of powders it is preferable to use the Kawakita equation and in case of larger agglomerates or granules to use the Adams equation, where the $\tau_{0}$ parameter has a more physical meaning.

Tab. 2 Compaction equations parameters with linear regression analyzes

\begin{tabular}{llrr}
\hline Compaction equation & Parameter & Value & Coefficient of deter. $R^{2}$ \\
\hline Heckel & $P_{y}$ & $78,31 \mathrm{MPa}$ & 0,99926 \\
\hline Kawakita & $P_{k}$ & $12,67 \mathrm{MPa}$ & 0,99983 \\
\hline \multirow{3}{*}{ Cooper-Eaton } & $a_{1}$ & 0,392 & \\
\cline { 2 - 3 } & $k_{1}$ & $2,096 \mathrm{MPa}$ & 0,99921 \\
\cline { 2 - 4 } & $a_{2}$ & 0,599 & \\
\cline { 2 - 4 } & $k_{2}$ & $17,419 \mathrm{MPa}$ & 0,99918 \\
\hline
\end{tabular}

All compaction equations parameters are published in [10].

\section{Conclusion}

This paper was focused on the analysis of the compressibility of one of the most widely used excipients in the technology of pharmaceutical tablet manufacturing. Compressibility was assessed on the basis of generally accepted, and in the practical experience most commonly used, compaction equations. The results show that MCC Avicel PH102 can be analyzed by all the above compaction equations, thus their graphical representations show an appropriate curve to create regression analysis, on the basis of which it is possible to determine the required parameters. The powder already has a considerable plastic behaviour at low porosity reduction, which represents a significant linear area in compaction equations plots. Only the Adams equation's use seems questionable, whose main parameter shows the strength of the agglomerate expressed from the die compaction test. Its uses should have more physical meaning in the case of granules or larger agglomerates.

Properties of the experimental material were obtained by different measurement methods on state of art equipment. Knowledge of these characteristics greatly facilitates a prediction of the behaviour of the powder during its processing in the various technologies and are used as input data for calculations and computer simulations. 


\section{Acknowledgement}

This article was created with the support of the Ministry of Education, Science, Research and Sport of the Slovak Republic within the Research and Development Operational Programme for the project "University Science Park of STU Bratislava", ITMS 26240220084, co-funded by the European Regional Development Fund.

This article was created within the grant project "Analysis of the thermo-mechanical properties of powder material during uniaxial compression in the pharmaceutical industry" within the program of support for excellent teams of young researchers at the Slovak University of Technology.

The authors would like to thank IMCD Czech Republic, s r.o., Praha for their cooperation in the research projects and B\&K Ltd. Bratislava for the design and implementation of the unique electromechanical press with programmable control for research compression of the particulate materials under non-standard conditions.

\section{References}

[1] ADAMS, M.J., MCKEOWN, R.: Micromechanical analysis of the pressure-volume relationships for powders under confined uniaxial compression. Powder Technology, 88, 1996, pp. 155-163

[2] ANTIKAINEN, O., YLIRUUSI, J.: Determining the compression behavior of pharmaceutical powders from the force-distance compression profile. International Journal of Pharmacology, 252, 2003, pp. 253-261

[3] AUGSBUtGer, L. L., HOAG, S.W.: Pharmaceutical Dosage Forms: Tablets. New York: Informa Healtcare USA, 2008

[4] CELIK, M.: The Past, Present, and Future of Tabletting Technology. Drug Development and Industrial Pharmacy, 22, 1996, pp. 1-10

[5] CHOWHAN, Z.T., CHOW, Y.P.: Compression behavior of pharmaceutical powders. Journal of Pharmaceutical Sciences, 5, 1980, pp. 139-148

[6] CUNNINGHAM, J.C., SINKA, I.C., ZAVALIANGOS, A.: Analysis of Tablet Compaction. I. Characterization of Mechanical Behavior of Powder and Powder/Tooling Friction. Pharmaceutical Technology, 93, 2004, pp. 2022-2039

[7] DECROSTA, M.T., SCHWARTZ, J.B., WIGENT, R.J., MARSHALL, K.: Thermodynamic analysis of compact formation; compaction, unloading, and ejection I. Desing and development of a compaction calorimeter and mechanical and thermal energy determinations of powder compaction. International Journal of Pharmaceutics, 198, 2000, pp. 113-134

[8] DECROSTA, M.T., SCHWARTZ, J.B., WIGENT, R.J., MARSHALL, K.: Thermodynamic analysis of compact formation; compaction, unloading, and ejection II. Mechanical energy (work) and thermal energy (heat) determinations of compact unloading and ejection. International Journal of Pharmaceutics, 213, 2001, pp. 45-62

[9] DENNY, P.J.: Compaction equations: A comparison of the Heckel and Kawakita equations. Powder Technology, 127, 2002, pp. 162-172

[10] ECKERT, M., PECIAR, P., KROK, A., FEKETE, R.: Application of Compaction Equations for Powdered Pharmaceutical Materials. Scientific Proceedings Faculty of Mechanical Engineering, 23, 2016, pp. 6-11 
[11] FREEMAN, R.: Measuring the flow properties of consolidated, conditioned and aerated powders - A comparative study using a powder rheometer and a rotational shear cell. Powder Technology, 174, 2007, pp. 25-33

[12] GABAUDE, C., GUILLOT, M., GAUTIER, J.C.: Effects of true density, compacted mass, compression speed, and punch deformation on the mean yield pressure. Journal of Pharmaceutical Sciences, 88, 1999, pp. 725-730

[13] HAN, L.H., ELLIOT, J.A., BENTHAM, A.C., MILLS, A. AMIDON, G.E.: A modified Drucker-Prager Cap model for die compaction simulation of pharmaceutical powders. International Journal of Solid and Structures, 45, 2008, pp. 3088-3106

[14] KAWAKITA, K.: Some considerations on powder compression equations. Powder Technology, 4, 1971, pp. 61

[15] KIEKENS, F., DEBUNNE, A., VERVAET, C.: Influence of the punch diameter and curvature on the yield pressure of MCC-compacts during Heckel analysis. European Journal of Pharmacology, 22, 2004, pp. 117-126

[16] KLINZING, G.R., ZAVALIANGOS, A., CUNNINGHAM, J., MASCARO, T.: Temperature and density evolution during compaction of a capsule shaped tablet. Computers and Chemical Engineering, 34, 2010, pp. 1082-1091

[17] KROK, A., PECIAR, M. FEKETE, R.: Numerical investigation into the influence of the punch shape on the mechanical behavior of pharmaceutical powders during compaction. Particuology, 16, 2013, pp. 116-131

[18] MAHMOODI, F.: Compression Mechanics of Powders and Granular Materials Probed by Force Distributions and a Micromechanically Based Compaction Equation. Uppsala: Acta Universitatis Upsaliensis, 2012

[19] NICKLASSON, F., ALBETBORN, G.: Analysis of the compression mechanics of pharmaceutical agglomerates of different porosity and composition using the Adams and Kawakita equations. Pharmaceutical Research, 17, 2009, pp. 49-954

[20] ROUÉCHE, E., SERRIS, E., THOMAS, G., CAMBY, L.: Influence of temperature on compaction of an organic powder and the mechanical strength of tablets. Powder Technology, 162, 2006, pp. 138-144

[21] SHANG, C., SINKA, I.C., PAN, J.: Constitutive Model Calibration for Powder Compaction Using Instrumented Die Testing. Society for Experimental Mechanics, 98, 2011, pp. 69-75

[22] SHI, L., CHATTORAJ, S., SUN, C.C.: Reproducibility of flow properties of microcrystalline cellulose - Avicel PH102. Powder Technology, 212, 2011, pp. 253-257

[23] SONNERGAARD, J.M.: A critical evaluation of the Heckel equation. International Journal of Pharmacology, 193, 1999, pp. 63-71

[24] SONNERGAARD, J.M.: Impact of particle density and initial volume on mathematical compression models. European Journal of Pharmaceutical Sciences, 11, 2000, pp. 307315

[25] SØgAARD, S., BRYDER, M., ALLESØ, M., RANTANEN, J.: Characterization of powder properties using a powder rheometer. Proceedings of Electronic Conference on Pharmaceutical Sciences, 2, 2012 
[26] Tablets (compressi). European Pharmacopoeia, Directorate for the Quality of Medicines and Health Care of the Council of Europe, 1, 2008

[27] WASHINGTON, C.: Particle size analysis in pharmaceutics and other industries. CRC Press, 1992

[28] WIACEK, J., MOLENDA, M.: Effect of particle size distribution on micro- and macromechanical response of granular packings under compression. International Journal of Solids and Structures, 51, 2014, pp. 4189-4195

[29] WU, C.Y., RUDDY, O.M., BENTHAM, A.C., HANCOOK, B.C., BEST, S.M.: Modelling the mechanical behavior of pharmaceutical powders during compaction. Powder Technology, 152, 2005, pp. 107-117

[30] YORK, P., PILPEL, N.: The effect of temperature on the mechanical properties of some pharmaceutical powders in relation to tabletting. Journal of Pharmacy and Pharmacology, 24, 1972, pp. 47-56

[31] ZAVAliAngOS, A., GALEN, S., CUNNINGHAM, J.: Temperature Evolution during Compaction of Pharmaceutical Powders. Pharmaceutical Technology, 97, 2008, pp. 3291-3304

[32] GOGA V., HUČKO B.: Phenomenological Material Model of Foam Solids. In Journal of Mechanical Engineering - Strojnícky časopis, Vol. 65, No. 1, 2015, pp. 5-20, ISSN 0039-2472 